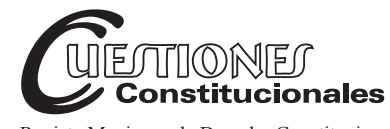

Revista Mexicana de Derecho Constitucional Núm. 43, julio-diciembre 2020

\title{
Las normas de ius cogens como imperativo en los procesos de justicia transicional. Estudio relativo al Tribunal de Jurisdicción Especial para la Paz en Colombia
}

\author{
The rules of ius cogens as an imperative in transitional justice \\ processes: a study relating to Colombia's Special Jurisdiction \\ for Peace Tribunal
}

\section{Yennesit PALACIOS VALENCIA*}

\begin{abstract}
RESUMEN: Colombia se está enfrentando a un proceso complejo de justicia transicional, no solo por la exigencia constante de los movimientos sociales, sino por la presión internacional, la necesidad sentida de justicia y, sobre todo, por el clamor de las víctimas. Lo cual ha permitido el impulso de un conjunto de reformas para cambiar la huella del pasado conflictivo. Lo anterior, soportado en un amplio andamiaje jurídico que intenta responder a las víctimas y a la misma sociedad con criterios de verdad, justicia, reparación y medidas de no repetición, dando como resultado lo que hoy se conoce como el Marco Jurídico para la Paz. En este contexto, los crímenes cometidos en el pasado serán juzgados por un Tribunal Especial para la Paz que, bajo la hipótesis sustentada, deberá ceñirse a las normas de ius cogens como estándar de obligatorio cumplimiento derivado del sistema jurídico internacional.
\end{abstract}

ABSTRACT: Colombia is facing a complex process of transitional justice, not only because of the constant demand of social movements, but also because of international pressure, a felt need for justice and, above all, for the clamor of the victims. This has allowed for a series of reforms to change the footprint of the conflicting past. The above, supported by a wide legal framework that seeks to respond to victims and civil society, with criteria of truth, justice, reparation and measures of nonrepetition, resulting in what is now known as the Legal Framework for Peace. In this context, crimes committed in the past will be judged by a Special Tribunal for Peace, which, under the assumption, should adhere to the norm of ius cogens as obligatory compliance standard derived from the international legal system.

* PhD en Derechos Humanos y Desarrollo de la Universidad Pablo de Olavide (UPO); abogada de la USB Medellín, Colombia. ORCID: 0000-0003-3581-439X. Correo electrónico:yennesit.palacios@gmail.com. 
Palabras clave: crímenes internacionales, Colombia, ius cogens, justicia transicional, Tribunal Especial para la Paz.
Keywords: international crimes, Colombia, ius cogens, transitional justice, Special Court for Peace.

SUMARIO: I. Antecedentes generales. II. La función del Tribunal Especial para la Paz con control de convencionalidad. III. El ejercicio del Tribunal Especial para la Paz acorde a los estándares internacionales y a las normas de ius cogens.

IV. Conclusiones. V. Bibliografia.

\section{ANTECEDENTES GENERALES}

El 2012 fue un año en que las Fuerzas Armadas Revolucionarias de Colombia - más conocidas como las FARC o FARC-EP - y el gobierno del expresidente Juan Manuel Santos iniciaron en La Habana, Cuba, diálogos para un proceso de paz que incidiera en la terminación del conflicto armado, ${ }_{1}^{1}$ una ruta que diversos gobiernos habían intentado; no obstante, los resultados sobresalían por el fracaso, la complejidad y la continuidad del conflicto.

Esto ocurrió, como explica Uprimny, ${ }^{2}$ porque el debate sobre cómo enfrentar las violaciones masivas de derechos humanos en el marco de un proceso de paz reviste gran complejidad, por las dimensiones jurídicas, políticas y éticas que suelen presentar profundas tensiones entre sí. Estas tensiones se materializan en el enfrentamiento entre los imperativos jurídicos internacionales, que muestran una tendencia hacia la exigencia del castigo a los responsables de crímenes atroces, por un lado, y las restricciones derivadas de las realidades políticas y de la necesidad de lograr negociaciones exitosas para trascender el conflicto, por otro lado.

En este contexto, tuvieron que pasar alrededor de cuatro años para que la iniciativa liderada por el Premio Nobel de la Paz, Juan Manuel Santos, se concretara, finalmente, en un Acuerdo Paz, acto histórico ratificado el 26 de septiembre de 2016, para intentar acabar con un conflicto que data

1 Uprimny Yepes, Rodrigo et al., Justicia para la paz. Crímenes atroces, derecho a la justicia y paz negociada, Bogotá, Centro de Estudios de Derecho, Justicia y Sociedad, Dejusticia, 2014, p. 146 y ss.

2 Uprimny Yepes, Rodrigo y Botero Marino, Catalina (coords), ¿Justicia transicional sin transición? Verdad, justicia y reparación para Colombia, Bogotá, Centro de Estudios de Derecho, Justicia y Sociedad, 2006, p. 19.

Esta obra está bajo una Licencia Creative Commons

Atribución-NoComercial-SinDerivar 4.0 Internacional, IIJ-UNAM. 
aproximadamente de unos sesenta años, dejando millones de víctimas, muchas de ellas aún desplazadas por la violencia, y otras desaparecidas. ${ }^{3}$

Debe decirse que durante las negociaciones en La Habana ocurrieron acontecimientos inesperados: por un lado, tras casi cuatro años de negociación, dificultades y tensiones, los puntos acordados fueron sometidos a plebiscito, mecanismo de participación ciudadana consagrado en la Constitución Política de Colombia (artículo 103), regulado en la Ley 134 de 1994, como el pronunciamiento del pueblo convocado por el presidente de la República, mediante el cual apoya o rechaza una determinada decisión del Ejecutivo. No obstante, en un hecho excepcional la población colombiana optó por el NO, ante la pregunta por la aceptación de los Acuerdos de La Habana.

Esta situación debilitó los logros conseguidos; sin embargo, finalmente el texto quedó ratificado con seis puntos pactados entre las FARC y el gobierno, de la siguiente manera: punto 1. Sobre el Acuerdo de "Reforma Rural Integral"; unto 2. Acuerdo relativo a la "Participación política de las FARC-EP"; punto 3. Sobre el Acuerdo del "Cese al fuego y de hostilidades bilateral y definitivo y la dejación de las armas"; punto 4. Relativo al acuerdo de "Solución al problema de las drogas ilícitas"; punto 5. Acuerdo sobre las "Víctimas" del conflicto armado, y punto 6. Acuerdo relativo a los "Mecanismos de Implementación y Verificación". ${ }^{4}$

Ahora bien, en lo relativo al punto 5. Sobre víctimas, desde el Encuentro Exploratorio, en 2012, se acordó que el resarcimiento de las víctimas debería estar en el centro de cualquier acuerdo. Es por ello que se estableció la creación del Sistema Integral de Verdad, Justicia, Reparación y No Repetición (en adelante SIVJRNR o Sistema Integral), que contribuirá a la lucha contra la impunidad combinando mecanismos judiciales que permitan la investigación y sanción de las graves violaciones a los derechos humanos y las serias infracciones al derecho internacional humanitario, con mecanismos extrajudiciales complementarios que contribuyan al esclarecimiento de la verdad de lo ocurrido, la búsqueda de los desaparecidos y la reparación del daño causado a personas, a colectivos y a territorios

3 Centro Nacional de Memoria Histórica, Desaparición forzada. Balance de la contribución del CNMH al esclarecimiento histórico, Bogotá, CNMH, 2018.

4 Gobierno colombiano y las FARC-EP, Acuerdo Final para la terminación del conflicto y la Construcción de una paz estable y duradera, 2016, disponible en: https://www. jep.gov.co/Paginas/Normativa/Acuerdo-Final.aspx. 
enteros. Con relación al Sistema Integral, éste estará compuesto por cinco mecanismos y medidas, así:

a) La Comisión para el Esclarecimiento de la Verdad, la Convivencia y la No Repetición (en adelante la Comisión): será un órgano temporal y de carácter extrajudicial, que busca conocer la verdad de lo ocurrido y contribuir al esclarecimiento de las violaciones e infracciones y ofrecer una explicación amplia a toda la sociedad de la complejidad del conflicto; promover el reconocimiento de las víctimas y de las responsabilidades de quienes participaron directa e indirectamente en el conflicto armado, y promover la convivencia en los territorios para garantizar la no repetición.

La Comisión deberá cumplir tres objetivos fundamentales, que en su conjunto contribuyen a la no repetición del conflicto. En primer lugar, deberá contribuir al esclarecimiento de lo ocurrido y ofrecer una explicación amplia de la complejidad del conflicto, de tal forma que se promueva un entendimiento compartido en la sociedad, en especial de los aspectos menos conocidos del conflicto, como el impacto del conflicto en los niños, niñas y adolescentes y la violencia basada en género.

En segundo lugar, como se desprende de lo acordado, la Comisión deberá promover y contribuir al reconocimiento de las víctimas como ciudadanos y ciudadanas que vieron sus derechos vulnerados y como sujetos políticos de importancia para la transformación del país; el reconocimiento voluntario de responsabilidades individuales y colectivas por parte de todos quienes de manera directa o indirecta participaron en el conflicto como una contribución a la verdad, a la justicia, a la reparación y a la no repetición, y en general, el reconocimiento por parte de toda la sociedad de ese legado de violaciones e infracciones como algo que merece el rechazo de todos, y que no se debe ni se puede repetir.

En tercer lugar, la Comisión deberá promover la convivencia en los territorios, en el entendido de que la convivencia no consiste en el simple compartir de un mismo espacio social y político, sino en la creación de un ambiente transformador que permita la resolución pacífica de los conflictos y la construcción de la más amplia cultura de respeto y tolerancia en democracia.

b) Se crea también la Unidad Especial para la Búsqueda de Personas dadas por Desaparecidas en el Contexto y en Razón del Conflicto Armado: que será una unidad de carácter humanitario y extrajudicial, cuyo objetivo es dirigir, coordinar y contribuir a la implementación de acciones humanitarias de búsqueda e identificación de todas las personas dadas por 
desaparecidas en el marco del conflicto que se encuentren con vida y en los casos de fallecimiento, cuando sea posible, la localización y entrega digna de restos.

c) Por otra parte, se demanda una Jurisdicción Especial para la Paz (JEP), constituida por una serie de salas de justicia, entre las que se incluye una Sala de Amnistía e Indulto y un Tribunal Especial para la Paz (TEP), para administrar justicia e investigar, esclarecer, perseguir y sancionar las graves violaciones a los derechos humanos y las graves infracciones al derecho internacional humanitario. La JEP hace parte del Sistema Integral, y en su ejercicio, al ocuparse exclusivamente y de manera transitoria de las conductas relacionadas directa e indirectamente con el conflicto armado, no implica la sustitución de la jurisdicción ordinaria.

La JEP funcionará de manera especial para ejercer funciones judiciales de manera autónoma y preferente sobre los asuntos de su competencia, en especial respecto a conductas consideradas graves infracciones al derecho internacional humanitario o graves violaciones de los derechos humanos. Se aplicará únicamente a conductas cometidas con anterioridad a su entrada en vigor. Sin embargo, lo acordado también plantea que la responsabilidad de los destinatarios del SIVJRNR no exime al Estado de su deber de respetar y garantizar el pleno goce de los derechos humanos y de sus obligaciones, conforme al derecho internacional humanitario y al derecho internacional de los derechos humanos.

d) Como exigencia no menos importante, se instituye la creación de medidas de reparación integral para la construcción de la paz, que buscan asegurar la reparación integral de las víctimas, incluyendo los derechos a la restitución, la indemnización, la rehabilitación, la satisfacción y la no repetición, y la reparación colectiva de los territorios, las poblaciones y los colectivos más afectados por el conflicto y más vulnerables, en el marco de la implementación de los demás acuerdos. Con este fin, se fortalecerán los mecanismos existentes, se adoptarán nuevas medidas y se promoverá el compromiso de todos con la reparación del daño causado.

e) Finalmente, las garantías de no repetición: que serán el resultado, por una parte, de la implementación coordinada de todas las anteriores medidas y mecanismos, así como en general de todos los puntos del acuerdo final, y por la otra, de la implementación de medidas de no repetición que se acuerden en el marco del punto 3 -"Fin del Conflicto"-. ${ }^{5}$

\footnotetext{
5 Idem.
} 
Por lo tanto, teniendo en cuenta lo anteriormente descrito, el fin de este escrito es exponer al lector un acercamiento jurídico de fondo, sobre el escenario colombiano, en lo atinente al proceso de justicia transicional. El temario se concentra esencialmente en la función atribuida al Tribunal Especial para la Paz. Este ejercicio, a juicio de la autora, debe hacerse bajo el llamado que la jurisprudencia hace a los jueces, para que en la administración de justicia ejerzan control de convencionalidad teniendo en cuenta el imperativo de las normas de ius cogens.

No es gratuito que la Ley 1820 de 2016, "por medio de la cual se dictan disposiciones sobre amnistía, indulto y tratamientos penales especiales y otras disposiciones", consagre que no serán amnistiables las graves violaciones a los derechos humanos y las serias infracciones al derecho internacional humanitario cometidas en el contexto del conflicto armado, estándar internacional respetado por la comunidad internacional y ratificado por los diferentes sistemas de protección de los derechos humanos, de los cuales hace parte el Estado colombiano.

En esta coyuntura, en marzo de 2018, la Plenaria de la Jurisdicción Especial para la Paz, en ejercicio de la facultad conferida en el artículo transitorio 120 de la Constitución Política (Acto Legislativo 1o. de 2017, artículo 1o.), por el cual se adopta el Reglamento General de la Jurisdicción Especial para la Paz, adoptó las siguientes disposiciones normativas, entre las cuales destaca en su artículo 2o., que:

La JEP...; administra justicia de manera transitoria, independiente y autónoma y conoce de manera preferente sobre todas las demás jurisdicciones y de forma exclusiva de las conductas cometidas con anterioridad al 1 de diciembre de 2016, por causa, con ocasión o en relación directa o indirecta con el conflicto armado, por quienes participaron en el mismo, en especial respecto a conductas consideradas graves infracciones al Derecho Internacional Humanitario o graves violaciones de los Derechos Humanos...

En consecuencia, no se puede entonces excusar la comisión de conductas que vulneran claramente la conciencia misma de la humanidad, como los homicidios arbitrarios, las torturas, los tratos crueles, las tomas de rehenes, las desapariciones forzadas, los juicios sin garantías o la imposición de penas ex-post facto. ${ }^{6}$

6 Corte Constitucional, Sentencia C-225/95. Revisión de constitucionalidad del "Protocolo adicional a los Convenios de Ginebra del 12 de agosto de 1949, relativo a la 
Como corolario, se asume como hipótesis central que el Tribunal Especial para la Paz, máxima instancia de la JEP, deberá ceñirse, acorde a los estándares internacionales, a las normas de ius cogens y a las obligaciones internacionales contraídas en su nexo con el bloque de constitucionalidad y el control de convencionalidad, por varias razones; entre ellas aparecen estándares internacionales con efecto erga omnes y obligatoriedad, razón por la cual deben ser acatadas por todos los operadores jurídicos.

\section{LA FUNCIÓN DEL TRIBUNAL ESPECIAL PARA LA PAZ CON CONTROL DE CONVENCIONALIDAD}

\section{El Tribunal Especial para la Paz tendrá como función básica correspon-} der con los derechos de las víctimas a la verdad, justicia, reparación, y con ellos, a medidas de no repetición; el instrumento aplicable será el Marco Jurídico para la Paz, ${ }^{7}$ a propósito de la Ley de Amnistía e Indultos y otros tratamientos penales especiales, Ley 1820 de 2016, que no regirá para los delitos de lesa humanidad, genocidio y graves crímenes de guerra - esto es, toda infracción grave al derecho internacional humanitario cometida de forma sistemática - la toma de rehenes u otra privación grave de la libertad, la tortura, las ejecuciones extrajudiciales, la desaparición forzada, el acceso carnal violento y otras formas de violencia sexual, la sustracción de menores, el desplazamiento forzado, además del reclutamiento de menores, todo ello conforme a la tipología emanada del Estatuto de Roma (ER), de $1998,{ }^{8}$ instrumento del cual es parte el Estado colombiano.

Tampoco serán amnistiables, conforme lo establece la Ley 1820 de 2016, en su artículo 23, los delitos comunes que carecen de relación con la rebelión; es decir, aquellos que no hayan sido cometidos en el contexto

protección de las víctimas de los conflictos armados sin carácter internacional (Protocolo II)", 18 de mayo de 1995.

7 V. g. Congreso de la República, acto legislativo 01/2012, por medio del cual se establecen instrumentos jurídicos de justicia transicional en el marco del artículo 22 de la Constitución Política, y se dictan otras disposiciones, Bogotá, julio 21 de 2012; Acto legislativo 01, "por medio del cual se crea un título de disposiciones transitorias de la Constitución para la terminación del conflicto armado y la construcción de una paz estable y duradera y se dictan otras disposiciones", Bogotá, 4 de abril de 2017; Ley 1820 de 2016 , por medio de la cual se dictan disposiciones sobre amnistía, indulto y tratamientos penales especiales y otras disposiciones, Bogotá, 30 de diciembre de 2016.

8 Aprobado en Colombia mediante el decreto 2764 de 2002. 
y en razón de la rebelión durante el conflicto armado, o cuya motivación haya sido obtener beneficio personal, propio o de un tercero. Ahora bien, sólo serán amnistiables los delitos políticos y conexos, entendiendo por tales, aquellos en los cuales el sujeto pasivo de la conducta ilícita es el Estado y su régimen constitucional vigente. Lo establecido en este artículo no obsta para que se consideren delitos conexos con los delitos políticos aquellas conductas que hayan sido calificadas de manera autónoma como delitos comunes, siempre y cuando éstas se hubieran cometido en función del delito político y de la rebelión.

La Ley 1820 de 2016 que regirá para la jurisdicción especial para la paz es contemplada como un mecanismo de extinción de la acción penal, disciplinaria, administrativa y fiscal, que se concederá por los delitos políticos de "rebelión”, "sedición”, "asonada", "conspiración” y "seducción, usurpación y retención ilegal de mando" y los delitos que son conexos con éstos de conformidad con esta ley, ${ }^{9}$ lo cual no extingue el derecho de las víctimas a recibir reparación. En consecuencia, así como está estipulado en el Acuerdo sobre las Víctimas del Conflicto Armado, la responsabilidad de los destinatarios del SIVJRNR no exime al Estado de su deber de respetar y garantizar el pleno goce de los derechos humanos conforme al sistema jurídico internacional.

Así, la Ley 1820 consagra en su artículo 9 el deber del Estado de investigar, esclarecer, perseguir y sancionar conforme a los estándares internacionales en la materia, conexo a la figura del control de convencionalidad y el bloque de constitucionalidad. Esta última, como parámetro desarrollado por la misma Corte Constitucional en reiteradas sentencias, ${ }^{10}$ para incorporar de manera automática todos los tratados que versen sobre derechos humanos y áreas conexas al ordenamiento jurídico interno, y por el mandato de las normas de ius cogens, a todas las normas imperativas que no admiten acuerdo en contrario.

Así,

el bloque de constitucionalidad está compuesto por aquellas normas y principios que, sin aparecer formalmente en el articulado del texto constitucional, son utilizados como parámetros del control de constitucionalidad de las leyes, por cuanto han sido normativamente integrados a la Constitución, por diversas

9 Ley 1820 de 2016, artículo 15.

10 Corte Constitucional, sentencia T-878 de 2014; sentencia C-067 de 2003; sentencia C-582 de 1999; sentencia C-225 de 1995. 
vías y por mandato de la propia Constitución. Son pues verdaderos principios y reglas de valor constitucional, esto es, son normas situadas en el nivel constitucional, a pesar de que puedan a veces contener mecanismos de reforma diversos al de las normas del articulado constitucional stricto sensu. ${ }^{11}$

Esta corporación, en las sentencias citadas y en concordancia con la más autorizada doctrina y jurisprudencia internacionales, ha considerado que las normas de derecho internacional humanitario son parte integrante del ius cogens, así como también las normas imperativas derivadas del derecho internacional de los derechos humanos. Surge entonces

una verdadera integración jurídica entre el derecho interno de los países, en cuya cúpula se halla la Constitución Política y el derecho internacional cuando está de presente su ius cogens, dado que éste por representar valores superiores, inalienables e inajenables del individuo como son los Derechos Humanos, se coloca por encima de la misma normación internacional que pudiera desconocerlos y al mismo ius cogens habrá de acomodarse la legislación interna de los países. ${ }^{12}$

En efecto, la Corte Constitucional ha señalado que, salvo remisión expresa de normas superiores,

sólo constituyen parámetros de control constitucional aquellos tratados y convenios internacionales que reconocen derechos humanos (i) y, que prohíben su limitación en estados de excepción (ii). Es por ello que integran el bloque de constitucionalidad, entre otros, los tratados del derecho internacional humanitario, tales como los Convenios de Ginebra, los Protocolos I y II y ciertas normas del Pacto de San José de Costa Rica. ${ }^{13}$

Al mismo tiempo, a los Estados les rige el deber de adecuar no sólo su normativa interna conforme a los instrumentos internacionales en la materia, sino que los operadores jurídicos deben tener en cuenta las decisiones derivadas del sistema internacional de los derechos humanos por la figura del control de convencionalidad, que asiste la obligación correspondiente a los jueces y órganos vinculados a la administración de justicia, para fallar

\footnotetext{
11 Ibidem, sentencia C-225 de 1995.

12 Ibidem, sentencia C-027 de 1993.

13 Ibidem, sentencia C-582 de 1999.
} 
y actuar en la praxis jurídica conforme a la aplicación que del derecho internacional de los derechos humanos hacen los tribunales internacionales. Por tal razón, la misma Corte Constitucional ha reconocido que "el poder judicial está internacionalmente obligado a ejercer control de convencionalidad ex officio entre las normas internas y la Convención Americana". ${ }^{14}$

Al respecto, en el caso Boyce y otros vs. Barbados, ${ }^{15}$ la Corte Interamericana de Derechos Humanos (en adelante, Corte IDH) contextualizó de forma específica de qué manera debe ser implementado el control de convencionalidad en el ámbito interno. Explicó que los tribunales nacionales no sólo deben limitarse a realizar un examen de constitucionalidad de su normatividad, sino también de convencionalidad. En esta tarea, los jueces y órganos vinculados a la administración de justicia deben tener en cuenta no solamente los tratados que versen sobre derechos humanos, sino también la interpretación que del mismo ha hecho la Corte IDH como intérprete última, en este caso, de la Convención Americana de Derechos Humanos o Pacto de San José de Costa Rica (en adelante entiéndase Convención Americana). De tal manera, como se expresó en los casos Radilla Pacheco, ${ }^{16}$ Fernández Ortega ${ }^{17}$ y Rosendo Cantú, ${ }^{18}$ es necesario que las interpretaciones constitucionales y legislativas se adecuen al derecho internacional de los derechos humanos. ${ }^{19}$

Con lo cual, la hipótesis más fuerte que se asume es que el Tribunal Especial para la Paz (TEP) debe seguir, en estricto sentido, las normas de ius cogens y las obligaciones internacionales contraídas en su nexo con el bloque de constitucionalidad y el control de convencionalidad, pues la jurisprudencia emanada de los tribunales internacionales es parámetro de observancia, no sólo para los magistrados que constituyan el Tribunal Especial para la Paz, sino para cualquier operador jurídico.

14 Ibidem, sentencia C-500 de 2014.

15 Corte IDH, caso Boyce y Otros vs. Barbados, sentencia de excepción preliminar, fondo, reparaciones y costas, del 20 de noviembre de 2007, serie C, núm. 169.

16 Corte IDH, caso Radilla Pacheco vs. México, sentencia de excepciones preliminares, fondo, reparaciones y costas, del 23 de noviembre de 2009, serie C, núm. 209.

17 Fernández Ortega vs. México, sentencia de excepción preliminar, fondo, reparaciones y costas, del 30 de agosto del 2010, serie C, núm. 215.

18 Rosendo Cantú vs. México, interpretación de la sentencia de excepción preliminar, fondo, reparaciones y costas, 15 de mayo de 2011, serie C, núm. 225.

19 Caso Cabrera García y Montiel Flores vs. México, sentencia de excepción preliminar, fondo, reparaciones y costas, del 26 de noviembre de 2010, serie C, núm. 220. 
Por lo tanto, concluyentemente, a falta de estos parámetros, y, en ausencia de criterios de justicia, verdad y reparación, la implementación del Marco Jurídico para la Paz, con ellos los Acuerdos de La Habana, el proceso de paz podría correr el riesgo de ser un proceso fallido e ineficaz.

Recuérdese que el auge del derecho internacional de los derechos humanos y la influencia que ha tenido en los procesos de justicia transicional, entendiéndose por tal el corpus iuris creado en sociedades que han sufrido el impacto desproporcionado de múltiples manifestaciones de violencia, que se aplica excepcionalmente y de manera extraordinaria por tribunales ad hoc, para garantizar la consolidación de la paz, de manera estable y duradera - sin que ello implique el amparo de la impunidad o desatención de los estándares internacionales - ha permitido impregnar la normatividad existente no sólo a nivel constitucional, sino internacional, a través de la jurisprudencia y los mismos tratados internacionales — como pactos de obligatorio cumplimiento - . De esta manera, la configuración de los mismos se ha desarrollado de forma progresiva; por ello, los textos constitucionales suelen ser, por lo general, catálogos "vivos", de textura abierta, pues deben ir a la par de los fenómenos sociales, adecuándose también a la realidad social, razón por la cual se exige del derecho una transformación permanente y continua. De hecho, el artículo 93 de la Constitución colombiana, en consonancia con lo consagrado en el artículo 94, enlaza la figura del bloque de constitucionalidad con el control de convencionalidad, así:

Art. 93. Los tratados y convenios internacionales ratificados [entiéndase aprobados] por el Congreso, que reconocen los derechos humanos y que prohíben su limitación en los estados de excepción, prevalecen en el orden interno. Los derechos y deberes consagrados en esta Carta se interpretarán de conformidad con los tratados internacionales sobre derechos humanos ratificados por Colombia.

Art. 94. La enunciación de los derechos y garantías contenidos en la Constitución y en los convenios internacionales vigentes, no debe entenderse como negación de otros que, siendo inherentes a la persona humana, no figuren expresamente en ellos.

Lo anterior es capital precisarlo, toda vez que los diferentes convenios internacionales en materia de derechos humanos y otras áreas conexas otorgan pautas a seguir, de ahí el efecto impregnación que surten en el 
derecho doméstico, siendo una herramienta fundamental en cualquier proceso que afecte derechos humanos fundamentales, para moldear los textos normativos acorde a la realidad y necesidades actuales. Es por ello que las víctimas de graves violaciones a los derechos humanos e infracciones al derecho internacional humanitario, en el contexto colombiano, cuentan con un amplio y comprensivo corpus iuris internacional, que irradia a su vez los derechos emanados de la Constitución; es, por tanto, necesaria la aplicación de los respectivos estándares internacionales en materia de protección de derechos humanos por los operadores jurídicos.

En tal sentido, aunque algunos derechos no se encuentran de forma expresa en las Constitución como norma de normas, eso no quiere significar que no existan con contenido propio, máxime cuando tienen amplio desarrollo jurisprudencial y convencional en materia de derechos humanos. Esto es lo que explica por qué la exigencia del control de convencionalidad siempre se mantiene vigente como deber atribuido a los Estados en cabeza de los operadores jurídicos.

Sobre el particular, como exigencia derivada para los Estados aparecen en el derecho internacional de los derechos humanos, y particularmente en la Convención Americana, los derechos a las garantías judiciales y a la protección judicial, en sus artículos 8 y 25, respectivamente, derechos que tienen un fuerte contenido semántico en la lucha contra la impunidad, definida por la Corte IDH como "la falta en su conjunto de investigación, persecución, captura, enjuiciamiento y condena de los responsables de las violaciones de los derechos protegidos por la Convención Americana". ${ }^{20}$ La consecuencia inmediata es que como parámetro de control de convencionalidad, la Convención Americana se superpone como norma primaria superior, esto de conformidad con su artículo 2, que reza así: "los Estados están obligados a adoptar con arreglo a sus procedimientos constitucionales y a las disposiciones de esta Convención, las medidas legislativas o de otro carácter que fueren necesarias para hacer efectivos tales derechos y libertades".

Lo cual, para el caso sub examine, obliga al Estado colombiano a combatir la impunidad, aun el Marco Jurídico para la Paz, por todos los medios legales disponibles, pues la impunidad propicia la repetición crónica de las violaciones de derechos humanos y la total indefensión de las víctimas

20 Corte IDH, caso del Tribunal Constitucional vs. Perú, sentencia de fondo, reparaciones y costas, del 31 de enero de 2001, serie C, núm. 71; caso Bámaca Velásquez vs. Guatemala, sentencia de fondo, del 25 de noviembre de 2000, serie C, núm. 70. 
y de sus familiares. ${ }^{21}$ En tal sentido, la falta de recursos efectivos no sólo para combatir la impunidad, sino para garantizar el acceso a la justicia, contraviene un cúmulo de derechos, entre ellos el derecho a la verdad, que ha sido desarrollado vía jurisprudencial ampliamente a la luz de la Convención Americana.

Ante esta realidad, la Comisión Interamericana de Derechos Humanos $(\mathrm{CoIDH})$ ha sostenido que el derecho a la verdad no debe ser coartado a través de medidas legislativas o de otro carácter, como las leyes de amnistía. ${ }^{22}$ Así, en el caso de las Masacres de El Mozote y Lugares Aledaños, la Corte IDH dispuso que

El Salvador tendría que asegurar que la Ley de Amnistía General para la Consolidación de la Paz, cesara de representar un obstáculo para la investigación de los hechos materia del... caso, ni para la identificación, juzgamiento y eventual sanción de los responsables de los mismos y de otras graves violaciones de derechos humanos similares acontecidas durante el conflicto armado en El Salvador. ${ }^{23}$

Nótese que la Corte IDH obliga a seguir como parámetros de control de convencionalidad impedimentos fácticos o legales, tales como la expedición de leyes de amnistía y el acceso a la información sobre los hechos y circunstancias que rodean la violación de un derecho fundamental, que impida poner en marcha los recursos judiciales de la jurisdicción interna, porque resultan incompatibles con el derecho a la protección judicial previsto en el artículo 25 de la Convención Americana. El proceso destinado a establecer la verdad requiere del libre ejercicio del derecho a buscar y recibir información y la adopción de las medidas necesarias para habilitar al Poder Judicial a emprender y completar las investigaciones correspondientes. ${ }^{24}$

21 CoIDH, Verdad, justicia y reparación: cuarto informe sobre la situación de los derechos humanos en Colombia, OEA/Ser.L/V/II. Doc. 49/13, 31 diciembre 2013, párr. 201. Recuperado de: https://www.oas.org/es/cidh/docs/pdfs/justicia-verdad-reparaciones.pdf

22 Caso Barrios Altos vs. Perú, sentencia de fondo, 14 de marzo de 2001, serie C, núm. 75; caso Almonacid Arellano y otros vs. Chile, sentencia de excepciones preliminares, fondo, reparaciones y costas, 26 de septiembre de 2006, serie C, núm. 154.

23 Masacres de El Mozote y lugares aledaños vs. El Salvador, sentencia de fondo, reparaciones y costas, 25 de octubre de 2012, serie C, núm. 252.

24 CoIDH, Verdad, justicia y reparación..., cit., párr. 205.

Esta obra está bajo una Licencia Creative Commons Atribución-NoComercial-SinDerivar 4.0 Internacional, IIJ-UNAM. 
Igualmente, el control de convencionalidad obliga a seguir la interpretación que ha hecho la Corte IDH en sentido amplio respecto de los derechos amparados bajo la Convención Americana. Algunos de ellos constituyen aspectos claves en los procesos de justicia transicional, entre ellos el derecho a la verdad, asociado implícitamente con los derechos a las garantías judiciales y protección judicial, derechos que en determinados supuestos guardan relación con "el derecho de acceso a la información sobre graves violaciones de derechos humanos que se encuentran en instalaciones y archivos estatales". Siguiendo a la CoIDH y a la Corte IDH, también comprende una doble dimensión:

En primer lugar, se reconoce el derecho de las víctimas y sus familiares a conocer la verdad con respecto a los hechos que dieron lugar a graves violaciones de los derechos humanos... En segundo lugar, se ha consolidado la noción que este derecho no sólo corresponde a las víctimas y sus familiares, sino también a la sociedad en su conjunto... ${ }^{25}$

Recuérdese que el Comité de Derechos Humanos, el Tribunal Europeo de Derechos Humanos, la Corte IDH, la CoIDH y la Comisión Africana de Derechos Humanos y de los Pueblos han considerado que el hecho de no proporcionar información sobre violaciones de derechos humanos, y en específico "sobre la suerte y el paradero de los desaparecidos o sobre las circunstancias de una ejecución y el lugar exacto en el que se enterró a las víctimas, puede equivaler a tortura o maltrato. Sin embargo, el derecho a la verdad sigue siendo un derecho autónomo con su propia base jurídica". ${ }^{26}$

En consecuencia, acogiendo las bases que se derivan de los órganos e instrumentos internacionales, junto con la obligatoriedad de los operadores jurídicos para interpretar conforme a ellos, no se pueden desconocer los principios rectores originados de los tratados internacionales, pues marcan la pauta para el goce y ejercicio de los derechos contemplados en los distintos textos constitucionales, entre otras cosas, por una suerte de

25 CoIDH, Derecho a la verdad en Las Américas. OEA/Ser.L/V/II.152.Doc.2. 13 de agosto de 2014, párr. 15, disponible en: http://www.oas.org/es/cidh/informes/pdfs/Derecho-Verdad-es.pdf.

26 ONU, Promoción y protección de los derechos humanos. Estudio sobre el derecho a la verdad, E/CN.4/2006/91, de enero 9 de 2006, párr. 42, disponible en: http://www. concernedhistorians.org/content_files/file/to/120.pdf. 
constitucionalización del derecho internacional de los derechos humanos, vía control de convencionalidad y bloque de constitucionalidad en sede interna. Además, el principio pacta sunt servanda estipulado en la Convención de Viena de $1969^{27}$ impone como deber a los Estados, cumplir con las obligaciones derivadas de los tratados, puesto que en caso de incumplimiento procede responsabilidad internacional para el Estados parte.

En efecto, cuando un Estado es parte de un tratado internacional como la Convención Americana, todos sus órganos, incluidos sus jueces, están sometidos a aquél, lo cual les obliga a velar por que los efectos de las disposiciones de la Convención no se vean mermados por la aplicación de normas contrarias a su objeto y fin, por lo que, en conclusión, los jueces y órganos vinculados a la administración de justicia, en todos los niveles, están en la obligación de ejercer ex officio un "control de convencionalidad" 28 entre las normas internas y la Convención Americana, evidentemente, en el marco de sus respectivas competencias y de las regulaciones procesales. ${ }^{29}$

El Tribunal Especial para la Paz debe seguir ese imperativo, pues su ejercicio está amparado no sólo en el orden constitucional vigente, sino en las convenciones sobre derechos humanos, que dan sustento al mismo ordenamiento jurídico, junto con toda la normativa derivada, que exige verdad, justicia, reparación y medidas de no repetición, junto con la supresión de leyes de amnistía por la comisión de crímenes internacionales, en cuyo caso, en Colombia, la misma Ley de Amnistía e Indulto 1820 de 2016 estipula que le asiste al Estado como obligación derivada del derecho internacional de los derechos humanos, el deber de investigar, pues si con su actuación o en ausencia de ella las violaciones a los derechos humanos quedan impunes y no se restablece el daño causado, no estaría garantizando la protección efectiva de las personas bajo su tutela.

Por tanto, en garantía a los derechos de las víctimas, el Marco Jurídico para la Paz tuvo que ser objeto no sólo de control de constitucionalidad, sino de convencionalidad, habida cuenta que los tratados que versan sobre derechos humanos y la jurisprudencia derivada de las cortes inter-

\footnotetext{
27 Artículo 26.

28 Corte IDH, caso Heliodoro Portugal vs. Panamá, sentencia de excepciones preliminares, fondo, reparaciones y costas, 12 de agosto de 2008, serie C, núm. 186, párr. 180.

29 Caso Gelman vs. Uruguay, párr. 193; caso Rosendo Cantú y otra vs. México, párr. 219; caso Radilla Pacheco vs. México, párr. 339.
} 
nacionales prohíben las leyes de amnistía por la comisión de crímenes internacionales; por ello, sólo serán objeto de amnistía u otros eximentes de responsabilidad aquellos delitos considerados como políticos y conexos.

En tipología ha sido un concepto normativo empleado con tres fines plenamente diferenciables:

(i) permitir que a los condenados por estas conductas les sea otorgada una amnistía o les sea concedido un indulto; ejemplo de ello, es la consagración que desde 1991 se hizo en el numeral 17 del artículo 150 de la Constitución. (ii) Impedir que los perseguidos por conductas que se consideren delito político sean extraditados, tal y como lo prevé el tercer inciso del artículo 35 de la Constitución. (iii) Permitir que los condenados por estas conductas participen en política, específicamente para que puedan acceder a cargos públicos y ejercer el derecho de sufragio pasivo. ${ }^{30}$

Al tener en cuenta esta diferenciación, la Corte Constitucional ha establecido que resulta evidente que en instrumentos internacionales que forman parte del bloque de constitucionalidad y en diversas sentencias que conforman la jurisprudencia constitucional relativa a la materia se consagran límites respecto de: "i) la concesión de amnistías e indultos, así como ii) la prohibición de extradición de delincuentes por parte del Estado colombiano; límites que a su vez determinan cuáles delitos podrán considerarse como políticos o conexos a delitos políticos cuando estas categorías sean utilizadas con dichos fines". ${ }^{31}$ La particularidad de esta tipología de delitos en el ordenamiento jurídico colombiano es que no generan inhabilidad para el acceso a cargos públicos, como sí lo hacen los delitos comunes que implican pena privativa de la libertad.

Ahora bien, la misma Corte Constitucional, en sentencia C-579/13, tuvo que analizar si el "Marco Jurídico para la Paz" era incompatible con el pilar esencial que exige respetar, proteger y garantizar los derechos de la sociedad y de las víctimas, a través del cumplimiento de las obligaciones de investigar, juzgar y en su caso sancionar, las graves violaciones a los derechos humanos y al derecho internacional humanitario, justamente por el imperativo del control de convencionalidad.

\footnotetext{
30 Corte Constitucional, sentencia C-577 de 2014.

31 Idem.
} 
Al respecto, expresó:

existe un pilar fundamental de la Constitución que consiste en el compromiso del Estado social y democrático de derecho de respetar, proteger y garantizar los derechos de la sociedad y de las víctimas. En virtud de este mandato, existe la obligación de: (i) prevenir su vulneración; (ii) tutelarlos de manera efectiva; (iii) garantizar la reparación y la verdad; e (iv) investigar, juzgar y en su caso sancionar las graves violaciones a los Derechos Humanos y al Derecho Internacional Humanitario.

Consideró que para alcanzar una paz estable y duradera es legítimo adoptar medidas de justicia transicional, como los mecanismos de selección y priorización. La Sala examinó si la posibilidad de centrar esfuerzos en la investigación penal de los delitos de lesa humanidad, genocidio y crímenes de guerra cometidos de manera sistemática garantiza el cumplimiento de las obligaciones internacionales asumidas por Colombia, y concluyó que, en virtud de los instrumentos de derechos humanos y del derecho internacional humanitario, y los pronunciamientos de sus intérpretes, es legítimo que se dé una aplicación especial a las reglas de juzgamiento, siempre y cuando se asegure que, como mínimo, se enjuiciarán aquellos delitos. ${ }^{32}$

En cuanto a imputar los delitos sólo a sus máximos responsables, la Corte Constitucional consideró que el Estado no renuncia a sus obligaciones, por las siguientes razones:

(i) La concentración de la responsabilidad en los máximos responsables no implica que se dejen de investigar todos los delitos de lesa humanidad, genocidio y crímenes de guerra cometidos de manera sistemática, sino que permite que sean imputados solo a quienes cumplieron un rol esencial en su comisión; y (ii) se contribuye eficazmente a desvertebrar macroestructuras de criminalidad y revelar patrones de violaciones masivas de derechos humanos, asegurando en últimas la no repetición.

También analizó la renuncia condicionada a la persecución penal, y al respecto aclaró que la figura se encuentra limitada, por cuanto no aplica para los máximos responsables de los delitos de lesa humanidad, genoci-

32 Corte Constitucional, sentencia C-579 de 2013.

Esta obra está bajo una Licencia Creative Commons Atribución-NoComercial-SinDerivar 4.0 Internacional, IIJ-UNAM. 
dio $^{33}$ y crímenes de guerra cometidos de manera sistemática, conforme con los estándares internacionales.

Finalmente,

explicó que la renuncia condicionada a la persecución penal se justifica al ponderar la obligación de investigar, juzgar y en su caso sancionar, con el deber de prevenir futuras violaciones a los derechos humanos en la búsqueda de una paz estable y duradera... siempre que se encuentren orientados a satisfacer los derechos de las víctimas a la verdad, la justicia, la reparación y la no repetición, con observancia de los deberes estatales de investigación y sanción de las graves violaciones de los derechos humanos y el Derecho Internacional Humanitario. ${ }^{34}$

La jurisprudencia invocada evidencia de forma clara y contundente cómo opera la subsidiaridad del derecho internacional y su armonización a través del derecho interno, habida cuenta del necesario control de convencionalidad. No obstante, en virtud del principio de complementariedad, en caso de que el derecho vigente con la constitución de la JEP no sea suficiente para el esclarecimiento de los hechos con criterios de verdad, justicia y reparación, ora porque se desconocen los estándares internacionales en la materia, ora porque las FARC-EP incumplan lo pactado en los Acuerdos de La Habana, la intervención de los órganos del sistema interamericano - incluso los del sistema universal - y la competencia de la Corte Penal Internacional, siempre estará vigente, precisamente por tratarse de graves transgresiones a los derechos humanos y al derecho internacional humanitario, en cuya circunstancia, tales violaciones no prescriben.

\section{EL EJERCICIO DEL TRIBUNAL ESPECIAL PARA LA PAZ ACORDE A LOS ESTÁNDARES INTERNACIONALES Y A LAS NORMAS DE IUS COGENS}

Una vez aclarado lo anterior, es necesario invocar puntualmente la aplicabilidad de las normas de ius cogens en el marco del TEP, habida cuenta que el derecho internacional de los derechos humanos designa reglas de

\footnotetext{
33 Recuérdese la consagración de la tipología en la Convención para la Prevención y la Sanción del Delito de Genocidio de 1948.

34 Corte Constitucional, sentencia C-579 de 2013.
} 
carácter imperativos que no admiten acuerdo en contrario bajo la pena de nulidad absoluta. Por ello, estas normas ${ }^{35}$ tienen la característica de ser inderogables, obligatorias, con efecto erga omnes, es decir, rigen para todos los Estados, entre ellas el principio de igualdad y no discriminación, la prohibición de la tortura, ${ }^{36}$ los principios básicos de protección de los derechos humanos, la proscripción del uso de la guerra, la prohibición del delito de genocidio y de crímenes contra la humanidad, y con ellos, la prohibición de la desaparición forzada ${ }^{37}$ de personas y las leyes de amnistía, indultos y otros eximentes de responsabilidad, cuando contravengan bienes jurídicos superiores.

También son parte integrante del ius cogens

los principios del derecho internacional humanitario plasmados en los Convenios de Ginebra y en sus dos Protocolos, por el hecho de constituir un catálogo ético mínimo aplicable a situaciones de conflicto nacional o internacional, ampliamente aceptado por la comunidad internacional. En consecuencia, su fuerza vinculante proviene de la universal aceptación y reconocimiento que la comunidad internacional de Estados en su conjunto le ha dado al adherir a esa axiología y al considerar que no admite norma o práctica en contrario... Conviene tener en cuenta que tanto los tratados de derechos humanos en

35 Cepeda Rodríguez, Emerson, “Interrelación entre el ius cogens y el derecho blando. Derechos sociales y responsabilidad social corporativa en la justicia transicional", Revista de Derecho Público, Universidad de los Andes, Colombia, núm. 36, junio 2016, pp. 1-16. DOI: disponible en: http://dx.doi.org/10.15425/redepub.36.2016.02; Cançado Trindade, Antonio Augusto, Derecho internacional de los derechos humanos. Esencia y trascendencia del derecho internacional de los derechos humanos (votos en la Corte Interamericana de Derechos Humanos 1991-2006), México, Porrúa-Universidad Iberoamericana, 2007, pp. 82-83 y ss.; Cherif Bassiouni, Mahmoud, "International Crimes: «Jus Cogens» and «Obligatio Erga Omnes»", Law and Contemporary Problems, vol. 59, num. 4, Accountability for International Crimes and Serious Violations of Fundamental Human Rights, autumn, 1996, pp. 63-74; Cebada Romero, Alicia, "Los conceptos de obligación erga omnes, ius cogens y violación grave a la luz del nuevo proyecto de la CDI sobre responsabilidad de los Estados por hechos ilícitos", Revista Electrónica de Estudios Internacionales, núm. 4, junio 2002, obtenido de: http://www.reei.org/index. php/revista/num4/archivos/Cebada.PDF.

36 Convención contra la Tortura y otros Tratos o Penas Crueles, Inhumanos o Degradantes de 1984 y la Convención Interamericana para Prevenir y Sancionar la Tortura de 1985.

37 Convención Interamericana sobre Desaparición Forzada de Personas de 1994 y la Convención Internacional para la Protección de Todas las Personas contra las Desapariciones Forzadas de 2006. 
sentido estricto, como los convenios de derecho humanitario son normas de ius cogens que buscan, ante todo, proteger la dignidad de la persona humana. Son pues normatividades complementarias que, bajo la idea común de la protección de principios de humanidad, hacen parte de un mismo género: el régimen internacional de protección de los derechos de la persona humana. ${ }^{38}$

Las normas de ius cogens, siguiendo a Gómez-Robledo y Witker, ${ }^{39}$ soportan el orden público internacional; esto es, normas y principios generales que constituyen su fundamento estructural, y por esta razón no pueden ser remplazadas ni sustituidas sin que el sistema pierda sus características definitorias. ${ }^{40}$ En tal sentido, Cançado Trindade ${ }^{41}$ entiende que el acceso a la justicia y las garantías judiciales en el sentido de los artículos 25 y 8 de la Convención Americana, tomados conjuntamente, hacen parte del dominio del jus cogens. ${ }^{42}$

Con estas características, la Convención de Viena de 1969 estipula en su artículo 53, que todo tratado que en el momento de su celebración esté en oposición con una norma imperativa (jus cogens) de derecho internacional general será nulo, entendiendo por tal una norma aceptada y reconocida por la comunidad internacional de Estados en su conjunto ${ }^{43}$ como norma que no admite acuerdo en contrario, y que sólo puede ser modificada por una norma ulterior de derecho internacional general que tenga el mismo carácter. Por tanto, las potestades derivadas para el TEP no son ajenas a los

\footnotetext{
38 Corte Constitucional, sentencia C-225 de 1995.
}

39 Gómez-Robledo, Alonso y Witker Velázquez, Jorge (coords), Diccionario de derecho internacional, México, UNAM-Porrúa, 2001, p. 252.

40 Gómez-Robledo, Antonio, El ius cogens internacional. Estudio historico-critico, México, UNAM, Instituto de Investigaciones Jurídicas, 2003, p. 60.

41 Cançado Trindade, Augusto, "Reflexiones sobre los tribunales internacionales contemporáneos y la búsqueda de la realización del ideal de la justicia internacional”, Cursos de Derecho Internacional y Relaciones Internacionales de Vitoria-Gasteiz, Universidad del País Vasco, 2010, p. 35. Disponible en: www.ehu.eus/cursosderechointernacionalvitoria/ponencias/pdf/2010/2010_1.pdf. También puede consultarse Cançado Trindade, Augusto, "La ampliación del contenido material del ius cogens", 2007, p. 8, disponible en: http://www.oas.org/es/sla/ddi/docs/publicaciones_digital_XXXIV_curso_derecho_in ternacional_2007_Antonio_Augusto_Cancado_Trindäde.pdf.

42 Corte IDH, caso de la Masacre de Pueblo Bello vs. Colombia, sentencia de fondo, reparaciones y costas, 31 de enero de 2006, serie C, núm. 140. párr. 64.

43 Díaz Tolosa, Regina, "El reconocimiento del ius cogens en el ordenamiento jurídico chileno", Revista Chilena de Derecho, 41, núm. 2, 2014, p. 560, disponible en: http:// www.scielo.cl/pdf/rchilder/v41n2/art07.pdf. 
mandatos jurídicos internacionales; dicho de otra forma, las normas de ius cogens se imponen a la soberanía estatal, por cuanto los derechos humanos aparecen como límite al ejercicio del poder.

La naturaleza jurídica del Tribunal Especial para la Paz, que ya quedó descrita en acápites anteriores, y con ella la normativa derivada del Marco Jurídico para la Paz, da tratamientos especiales en materia penal a los integrantes de las FARC-EP, siempre y cuando las conductas infringidas sean delitos políticos y conexos. Este sería el máximo umbral de aplicación de la Ley de Amnistía e Indultos, pues para los crímenes internacionales está la prohibición tajante de aplicación de amnistías y otros eximentes de responsabilidad.

La cuestión es que, a pesar de la constitución de dicho marco normativo, hay delitos, como la desaparición forzada de personas, cuya prohibición está contemplada como una norma de ius cogens, que, de quedar impunes, abren la puerta no sólo a los órganos del sistema interamericano de derechos humanos, sino a la activación de la Corte Penal Internacional, teniendo en cuenta que por su naturaleza es un delito continuado que sólo culmina cuando aparece la presunta víctima o se tiene indicio de su paradero.

La caracterización pluriofensiva y continuada o permanente de la desaparición forzada, en el sistema interamericano,

se desprende no sólo de la propia definición del artículo III de la Convención Interamericana sobre Desaparición Forzada de Personas, los travaux préparatoires a ésta, su preámbulo y normativa, sino también de otras definiciones contenidas en diferentes instrumentos internacionales que, asimismo, señalan como elementos concurrentes y constitutivos de la desaparición forzada: a) la privación de la libertad; b) la intervención directa de agentes estatales o por la aquiescencia de éstos, y c) la negativa de reconocer la detención y de revelar la suerte o paradero de la persona interesada. ${ }^{44}$

Por tanto, implica de base un conjunto de violaciones simultáneas a diferentes derechos. Esta tipología requiere de un análisis sistémico y comprensivo, en razón de la pluralidad de conductas que, cohesionadas por un único fin, vulneran mientras subsistan, bienes jurídicos protegidos por el derecho internacional de los derechos humanos de manera permanente. ${ }^{45}$

\footnotetext{
44 Caso Radilla Pacheco vs. México, 2009, párr. 140.

45 Caso González Medina y Familiares vs. República Dominicana, 2012, párr. 129.
} 
Así, la Corte DIH ha establecido que la desaparición forzada de personas constituye una violación múltiple, ${ }^{46}$ que inicia con una privación de libertad contraria al artículo 7 de la Convención Americana. ${ }^{47}$ La Corte IDH instituyó a su vez, que el sometimiento de detenidos a cuerpos represivos oficiales, agentes estatales o particulares que actúen con su aquiescencia o tolerancia, que impunemente practiquen la tortura y el asesinato, representa, por sí mismo, una infracción al deber de prevención de violaciones a los derechos a la integridad personal y a la vida. Esto es lo que obliga una conexión necesaria entre la desaparición forzada con la violación simultánea de diferentes derechos humanos.

Los tribunales penales internacionales anteriores a la CPI también se han pronunciado invocando normas de ius cogens, entre ellas la prohibición de la tortura. El Tribunal Penal Internacional para la ex Yugoslavia (TIPY), por ejemplo, en el caso prosecutor (fiscal) vs. Furundzija afirmó:

cabe señalar que la prohibición de la tortura establecida en los tratados de derechos humanos consagra un derecho absoluto, que nunca puede ser derogado, ni siquiera en caso de emergencia (por este motivo la prohibición también se aplica a situaciones de conflicto armado). Esto está vinculado al hecho..., que la prohibición de la tortura es una norma imperativa o jus cogens. Esta prohibición es tan extensa que incluso el derecho internacional impide a los Estados expulsar, devolver o extraditar a una persona a otro Estado cuando existan motivos fundados para creer que la persona estaría en peligro de ser sometida a tortura. ${ }^{48}$

Estas disposiciones de los tratados imponen a los Estados la obligación de prohibir y castigar la tortura, así como de abstenerse de practicar la

\footnotetext{
46 Caso Gomes Lund y Otros ("Guerrilha do Araguaia”) vs. Brasil, 2012, párr. 103.

47 Ibidem, párr. 122.

48 International Tribunal for the Prosecution of Persons Responsible for Serious Violations of International Humanitarian Law Committed in the Territory of the Former Yugoslavia since 1991. Presecutor vs. Furundzija, case IT-95-17/1-T. Judgement. 10 december 1998, párr. 144. It should be noted that the prohibition of torture laid down in human rights treaties enshrines an absolute right, which can never be derogated from, not even in time of emergency (on this ground the prohibition also applies to situations of armed conflicts). This is linked to the fact, discussed below, that the prohibition on torture is a peremptory norm or jus cogens. This prohibition is so extensive that States are even barred by international law from expelling, returning or extraditing a person to another State where there are substantial grounds for believing that the person would be in danger of being subjected to torture (versión original).
} 
tortura a través de sus funcionarios. En el derecho internacional de los derechos humanos, que se refiere a la responsabilidad de los Estados más que a la responsabilidad penal individual, la tortura está prohibida como delito penal y es sancionada por la legislación nacional. Además, todos los Estados partes en los tratados pertinentes han reconocido y están obligados a ejercer la jurisdicción para investigar, perseguir y castigar a los infractores. Por lo tanto, en la legislación de derechos humanos también la prohibición de la tortura se extiende y afecta directamente la responsabilidad penal de las personas. ${ }^{49}$

Ahora bien, la prohibición de la tortura es tan estricta que para prevenir su ocurrencia no basta con intervenir después de la imposición de la tortura, cuando la integridad física o moral de los seres humanos ya ha sido irremediablemente dañada.

Los Estados están obligados a poner en práctica todas las medidas que puedan prevenir la perpetración de la tortura, tal como lo expresó el Tribunal Europeo de Derechos Humanos en Soering vs. Reino Unido, el derecho internacional tiene la intención de prohibir no sólo las infracciones reales, sino también las violaciones potenciales de la prohibición de la tortura (así como cualquier trato inhumano y degradante).

De esto se desprende que las normas internacionales prohíben no sólo la tortura, sino también (i) la falta de adopción de las medidas nacionales necesarias para aplicar la prohibición (ii) y el mantenimiento en vigor o la aprobación de leyes contrarias a la prohibición. ${ }^{50}$

Esta exigencia se mantiene latente y vigente en todos los sistemas de responsabilidad, tanto para los Estados en el sistema regional y universal como para las personas en el ámbito de la Corte Penal Internacional (CPI), situación que explica cómo la no aplicación de estos principios básicos activaría no sólo el sistema penal derivado del ER, sino la responsabilidad para los Estados en los diferentes sistemas de protección de los derechos humanos.

Ahora bien, teniendo en cuenta el carácter de ius cogens del acceso a la justicia y las garantías judiciales — recuérdese que Colombia tenía una reserva que fue propuesta durante el gobierno del expresidente Andrés Pastrana, que se ratificó durante el gobierno del expresidente Álvaro Uribe-

\footnotetext{
49 Ibidem, párr. 145

50 Ibidem, párr. 148.
} 
en relación a la competencia de la CPI para conocer de crímenes de guerra, bajo el pretexto de impulsar un acuerdo de paz que diera terminación al conflicto, $\mathrm{y}$, por tanto, la jurisdicción de la CPI no se convirtiera en un obstáculo para dicho propósito, lo cual impidió que en el marco del ER la CPI pudiera investigar por un lapso de siete años crímenes de guerra para el caso de Colombia, terminándose dicha reserva en 2009.

Sin embargo, la competencia de la CPI estuvo vigente desde 2002 en relación con crímenes de lesa humanidad y genocidio, hecho que deja otra ventana abierta, en caso de que no se satisfaga con el Tribunal Especial para la Paz el derecho de las víctimas con criterio de justica, para que la CPI reabra investigaciones por estos dos crímenes, pues conforme al artículo 17, relativo a las cuestiones de admisibilidad, el ER prevé que no haya litispendencia, y que no opere la cosa juzgada, ${ }^{51}$ pues la CPI no puede fallar, entre otras cosas, con base en los mismos hechos y delitos incoados por otro tribunal competente, recuérdese el artículo 20 del ER:

1. La Corte no procesará a nadie que haya sido procesado por otro tribunal en razón de hechos también prohibidos en virtud de los artículos 6 , 7 u 8, a menos que el proceso en el otro tribunal:

a) Obedeciera al propósito de sustraer al acusado de su responsabilidad penal por crímenes de la competencia de la Corte, o

b) No hubiera sido instruido en forma independiente o imparcial de conformidad con las debidas garantías procesales reconocidas por el derecho internacional o lo hubiera sido de alguna manera que, en las circunstancias del caso, fuera incompatible con la intención de someter a la persona a la acción de la justicia.

Con relación a lo anterior, la CPI puede valorar si la decisión adoptada por el Tribunal Especial para la Paz ha sido, dado el caso, con el propósito de sustraer a la persona de que se trate de su responsabilidad penal por crímenes de la competencia de la Corte para proceder a investigar conforme lo estipula el ER.

Otro asunto de sumo cuidado es el retardo injustificado con relación al llamado de justicia de las presuntas víctimas, pues si en un plazo razonable, teniendo en cuenta la complejidad del asunto y la gravedad de los hechos, no hay decisión de fondo por el Tribunal Especial para la Paz, queda la interpretación abierta sobre si la Fiscalía de la CPI podría investigar motu proprio, debido al retardo injustificado. La Corte IDH, por ejemplo,

\footnotetext{
51 Artículo 20 del ER.
} 
en el caso Las Palmeras vs. Colombia, basándose en casos anteriores, por ejemplo, Genie Lacayo vs. Nicaragua ${ }^{52}$ estipuló que un término superior a cinco años rebasa los límites de la razonabilidad prevista por el artículo 8.1 de la Convención; por lo tanto, entendió que la víctima no estaba obligada a soportar la negligencia por la mora en la administración de justicia.

Acorde a lo anterior, la Corte IDH ha señalado que no pueden considerarse efectivos aquellos recursos que, por las condiciones generales del país o incluso por las circunstancias particulares de un caso dado, resulten ilusorios. Ello puede ocurrir, por ejemplo, cuando su inutilidad haya quedado demostrada por la práctica, porque el órgano jurisdiccional carezca de la independencia necesaria para decidir con imparcialidad o porque falten los medios para ejecutar sus decisiones; por cualquier otra situación que configure un cuadro de denegación de justicia, como sucede cuando se incurre en retardo injustificado en la decisión. Esta garantía de protección de los derechos de los individuos no supone sólo el resguardo directo a la persona vulnerada, sino, además, a los familiares, quienes, por los acontecimientos y circunstancias particulares del caso, son quienes ejercen la reclamación en el orden interno. Además, la Corte IDH ha manifestado que del artículo 8 de la Convención Americana se desprende que las víctimas de las violaciones de los derechos humanos, o sus familiares, deben contar con amplias posibilidades de ser oídos y actuar en los respectivos procesos, tanto en procura del esclarecimiento de los hechos y del castigo de los responsables como en busca de una debida reparación. ${ }^{53}$

En el mismo sentido, la CPI podría basarse en los precedentes del sistema interamericano para hacer la misma interpretación, si fuera el caso, teniendo en cuenta no sólo la complejidad del asunto, sino los parámetros perseguidos con el artículo 17.2 del ER, pues consagra que procede la admisibilidad de un caso, siempre,

... b) Que haya habido una demora injustificada en el juicio que, dadas las circunstancias, sea incompatible con la intención de hacer comparecer a la persona de que se trate ante la justicia; c) Que el proceso no haya sido o no esté siendo sustanciado de manera independiente o imparcial y haya sido o esté siendo sustanciado de forma en que, dadas las circunstancias, sea incompatible con la intención de hacer comparecer a la persona de que se trate ante la justicia.

52 Caso Genie Lacayo vs. Nicaragua, 1997, párr. 81.

53 Caso Las Palmeras vs. Colombia, 2000, párr. 59.

Esta obra está bajo una Licencia Creative Commons Atribución-NoComercial-SinDerivar 4.0 Internacional, IIJ-UNAM. 
Por otra parte, los criterios de la CPI respecto a su admisibilidad y competencia por crímenes internacionales pueden, vía interpretación, ser extensivos, conforme a los precedentes de otros tribunales, toda vez que el ER, en su artículo 21, estipula, con relación al derecho aplicable, que

1. La Corte aplicará:

a) En primer lugar, el... Estatuto, los Elementos de los crímenes y sus Reglas de Procedimiento y Prueba;

b) En segundo lugar, cuando proceda, los tratados aplicables, los principios y normas del derecho internacional, incluidos los principios establecidos del derecho internacional de los conflictos armados;...

2. La Corte podrá aplicar principios y normas de derecho respecto de los cuales hubiere hecho una interpretación en decisiones anteriores.

3. La aplicación e interpretación del derecho de conformidad con el presente artículo deberá ser compatible con los derechos humanos internacionalmente reconocidos...

La conclusión inmediata es que debido a los imperativos derivados de las normas de ius cogens, el TEP, con la aplicación de la Jurisdicción Especial para la Paz, debe vincular, en interpretación extensiva, los precedentes de la CPI, con los restantes en la materia, en otros tribunales penales internacionales y cortes de protección de derechos humanos por control de convencionalidad, siempre que esos principios no sean incompatibles con el derecho interno ni con el orden internacional ni con las normas y estándares internacionalmente reconocidos.

\section{CONCLUSIONES}

Lo explicado deja suficiente claridad con relación a que el derecho internacional de los derechos humanos, el derecho internacional humanitario y el sistema del ER son un todo armonioso que rigen de manera íntegra en la coyuntura actual colombiana, con lo cual, su observancia, por todo lo expuesto, es obligatoria, teniendo cuenta la fuerza de las normas de ius cogens y la principialística derivada. Máxime, cuando la CPI y la Corte IDH no están exentas de intervenir, en caso de que se diera cualquiera de las circunstancias anteriormente explicadas: 
1. Retardo injustificado en las decisiones del Tribunal Especial para la Paz;

2. Incompatibilidad en la tipología de crímenes con las leyes de amnistía;

3. Falta de independencia e imparcialidad del Tribunal Especial para la Paz;

4. Y, por último, y no menos importante, incongruencia en las decisiones con relación a los derechos de verdad, justicia, reparación y medidas de no repetición, de conformidad con los estándares internacionales en la materia.

En suma, este escrito es una descripción sensata y no menos rigurosa, en el estudio jurídico posible, sobre la aplicabilidad de las normas de ius cogens en las providencias del Tribunal Especial para la Paz, pues en todo caso estas normas se imponen sobre el Marco Jurídico para la Paz, bajo la pena de responsabilidad internacional. Esto implica, por tanto, que investigar y sancionar crímenes por graves violaciones a los derechos humanos e infracciones al derecho internacional humanitario conforme a los estándares internacionales no es una opción, es una obligación.

Por otra parte, se hace hincapié en que la JEP, acorde a su mandato, no sustituirá a la jurisdicción ordinaria, si bien asumirá casos con ocasión o en relación directa o indirecta con el conflicto armado, por quienes participaron en el mismo, sólo serán amnistiables los delitos políticos y conexos. Esto, se reitera, no exime al Estado de su deber de respetar y garantizar los estándares internacionales emanados del derecho internacional de los derechos humanos, concretados en múltiples tratados internacionales, que en Colombia hacen parte del bloque de constitucionalidad, y que bajo la jurisprudencia de la Corte IDH también vinculan al Estado por la figura del control de convencionalidad.

Finalmente, los estándares internacionales en la materia son claros, al demandar la creación de medidas de reparación integral para asegurar la reparación integral de las víctimas, incluyendo los derechos a la restitución, la indemnización, la rehabilitación, la satisfacción y la no repetición, elementos indispensables para garantizar el éxito de los Acuerdos de La Habana y, con ellos, la Jurisdicción Especial para la Paz. 


\section{BiBLIOGRAFÍA}

Cançado Trindade, Antonio Augusto, "Reflexiones sobre los tribunales internacionales contemporáneos y la búsqueda de la realización del ideal de la justicia internacional", Cursos de derecho internacional y relaciones internacionales de Vitoria-Gasteiz, País Vasco, Universidad del País Vasco, 2010. Disponible en: www.ehu.eus/cursosderechointernacionalvitoria/ponencias/pdf/2010/2010_1.pdf.

Cançado Trindade, Antonio Augusto, Derecho internacional de los derechos humanos. Esencia y trascendencia del derecho internacional de los derechos humanos (votos en la Corte Interamericana de Derechos Humanos 1991-2006), México, Porrúa-Universidad Iberoamericana, 2007.

CAnÇAdo Trindade, Antonio Augusto, "La ampliación del contenido material del ius cogens", 2007. Disponible en: http://www.oas.org/es/ sla/ddi/docs/publicaciones_digital_XXXIV_curso_derecho_internacional_2007_Antonio_Augusto_Cancado_Trindade.pdf.

CeBADA Romero, Alicia, "Los conceptos de obligación erga omnes, ius cogens y violación grave a la luz del nuevo proyecto de la CDI sobre responsabilidad de los Estados por hechos ilícitos", Revista Electrónica de Estudios Internacionales, núm. 4, junio 2002. Disponible en: http:// www.reei.org/index.php/revista/num4/archivos/Cebada.PDF.

Centro Nacional de Memoria Histórica, Desaparición forzada. Balance de la contribución del CNMH al esclarecimiento histórico, Bogotá, CNMH, 2018.

CEPEDA RodríGuez, Emerson, "Interrelación entre el ius cogens y el derecho blando. Derechos sociales y responsabilidad social corporativa en la justicia transicional", Revista de Derecho Público, núm. 36, Colombia, Universidad de los Andes, 2016, DOI: http://dx.doi.org/10.15425/ redepub.36.2016.02.

Cherif BASsiouni, Mahmoud, "International Crimes: «Jus Cogens» and «Obligatio Erga Omnes»", Law and Contemporary Problems, vol. 59, núm. 4, Accountability for International Crimes and Serious Violations of Fundamental Human Rights, 1996.

Comisión Interamericana De Derechos Humanos, Derecho a la verdad en Las Américas. OEA/Ser.L/V/II.152.Doc.2. 13 de agosto de 
2014. Disponible en: http://www.oas.org/es/cidh/informes/pdfs/Derecho-Verdad-es.pdf.

COMISIÓn INTERAMERICANA DE DEREChOs Humanos, Verdad, justicia y reparación. Cuarto informe sobre la situación de los derechos humanos en Colombia. OEA/Ser.L/V/II. Doc.49/13. Disponible en: https://www. oas.org/es/cidh/docs/pdfs/justicia-verdad-reparacion-es.pdf.

DíAz TolosA, Regina, "El reconocimiento del ius cogens en el ordenamiento jurídico chileno". Revista Chilena de Derecho, 41, núm. 2, 2014, pp. 555-587. Disponible en: http://www.scielo.cl/pdf/rchilder/ v4ln2/art07.pdf.

GómEZ-RoBledo, Alonso, El ius cogens internacional. Estudio históricocrítico. México, UNAM, Instituto de Investigaciones Jurídicas, 2003.

Gómez-Robledo, Alonso y Witker VelÁzQuez, Jorge (coords), Diccionario de derecho internacional, México, UNAM-Porrúa, 2001.

ORgANIZACIÓN DE NACIONES UNIDAS, Promoción y protección de los derechos humanos, Estudio sobre el derecho a la verdad, E/CN.4/2006/91, 2006. Disponible en: http://www.concernedhistorians.org/content_files/file/to/120.pdf.

UPRIMNY YEPES, Rodrigo et al., Justicia para la paz. Crímenes atroces, derecho a la justicia y paz negociada, Bogotá, Centro de Estudios de Derecho, Justicia y Sociedad, Dejusticia, 2014.

UPRIMNY YEPES, Rodrigo y BOTERO MARINO, Catalina, ¿Justicia transicional sin transición? Verdad, justicia y reparación para Colombia, Bogotá, Centro de Estudios de Derecho, Justicia y Sociedad, 2006.

Fecha de recepción: 16 de noviembre de 2018.

Fecha de aceptación: 14 de octubre de 2019.

Esta obra está bajo una Licencia Creative Commons Atribución-NoComercial-SinDerivar 4.0 Internacional, IIJ-UNAM. 